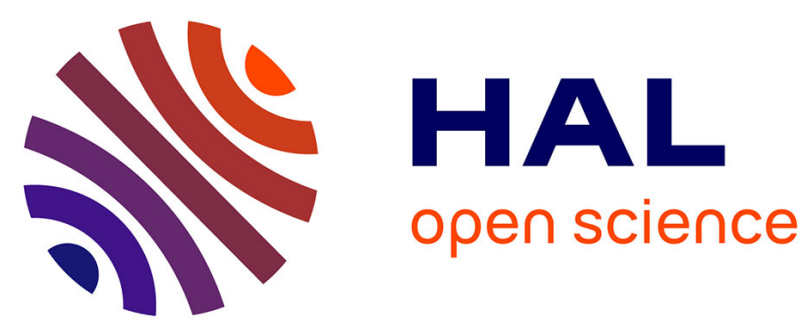

\title{
Experimental investigation of the effect of occupant characteristics on contemporary seat belt payout behavior in frontal impacts.
}

Bingbing Nie, David Poulard, Damien Subit, Jean-Paul Donlon, Jason.L Forman, Richard W. Kent

\section{To cite this version:}

Bingbing Nie, David Poulard, Damien Subit, Jean-Paul Donlon, Jason.L Forman, et al.. Experimental investigation of the effect of occupant characteristics on contemporary seat belt payout behavior in frontal impacts.. Traffic Injury Prevention, 2016, 17 (4), pp.374-380. 10.1080/15389588.2015.1088944. hal-02473262

\section{HAL Id: hal-02473262 \\ https://hal.science/hal-02473262}

Submitted on 10 Feb 2020

HAL is a multi-disciplinary open access archive for the deposit and dissemination of scientific research documents, whether they are published or not. The documents may come from teaching and research institutions in France or abroad, or from public or private research centers.
L'archive ouverte pluridisciplinaire HAL, est destinée au dépôt et à la diffusion de documents scientifiques de niveau recherche, publiés ou non, émanant des établissements d'enseignement et de recherche français ou étrangers, des laboratoires publics ou privés. 


\title{
Experimental investigation of the effect of occupant characteristics on contemporary seat belt payout behavior in frontal impacts
}

\author{
Bingbing Nie ${ }^{a}$, David Poulard ${ }^{a}$, Damien Subit ${ }^{b}$, John-Paul Donlon ${ }^{a}$, Jason L. Forman ${ }^{a}$, and Richard W. Kent ${ }^{a}$ \\ a University of Virginia, Center for Applied Biomechanics, Charlottesville, Virginia; ${ }^{b}$ Institut de Biomécanique Humaine Georges Charpak, Arts et Métiers \\ ParisTech, Paris, France
}

\begin{abstract}
Objective: The goal of this study was to investigate the influence of the occupant characteristics on seat belt force vs. payout behavior based on experiment data from different configurations in frontal impacts.

Methods: The data set reviewed consists of 58 frontal sled tests using several anthropomorphic test devices (ATDs) and postmortem human subjects (PMHS), restrained by different belt systems (standard belt, SB; force-limiting belt, FLB) at 2 impact severities ( 48 and $29 \mathrm{~km} / \mathrm{h}$ ). The seat belt behavior was characterized in terms of the shoulder belt force vs. belt payout behavior. A univariate linear regression was used to assess the factor significance of the occupant body mass or stature on the peak tension force and gross belt payout. Results: With the SB, the seat belt behavior obtained by the ATDs exhibited similar force slopes regardless of the occupant size and impact severities, whereas those obtained by the PMHS were varied. Under the 48 $\mathrm{km} / \mathrm{h}$ impact, the peak tension force and gross belt payout obtained by ATDs was highly correlated to the occupant stature $(P=.03, P=.02)$ and body mass $(P=.05, P=.04)$, though no statistical difference with the stature or body mass were noticed for the PMHS (peak force: $P=.09, P=.42$; gross payout: $P=.40, P=$ .48). With the FLB under the $48 \mathrm{~km} / \mathrm{h}$ impact, highly linear relationships were noticed between the occupant body mass and the peak tension force $\left(R^{2}=0.9782\right)$ and between the gross payout and stature $\left(R^{2}=0.9232\right)$ regardless of the occupant types.

Conclusions: The analysis indicated that the PMHS characteristics showed a significant influence on the belt response, whereas the belt response obtained with the ATDs was more reproducible. The potential cause included the occupant anthropometry, body mass distribution, and relative motion among body segments specific to the population variance. This study provided a primary data source to understand the biomechanical interaction of the occupant with the restraint system. Further research is necessary to consider these effects in the computational studies and optimized design of the restraint system in a more realistic manner.
\end{abstract}

\section{Introduction}

Occupant thoracic injuries account for up to $30 \%$ of traffic crash fatalities (Backaitis 1994; Mulligan et al. 1994). Seat belts act as an essential element in occupant restraint systems equipped on vehicles to decrease thoracic injuries when impacts occur (Fauziana et al. 2012; NHTSA 2011; Walz 2004). Seat belts have also proven to be effective for protection of rear seat occupants in full and offset frontal crash tests (Mizuno et al. 2011). However, restraining the shoulder with a standard belt (SB) has been shown to be related to thoracic injury risk and a too-high seat belt force may cause seat belt-related injuries (Abbas et al. 2011). Thresholds for the shoulder belt load have been proposed as a way to reduce the thoracic injury risk without negative consequences on other injury countermeasures (Foret-Bruno et al. 1998, 2001). Consequently, contemporary seat belt systems incorporate force-modulating components, such as pretensioners and multistage force-limiting belts (FLBs), which generate complex transient forces to the occupant's thorax (Bendjellal et al. 2011; Haland 2006; Lopez-Valdes et al. 2014).

\author{
KEYWORDS \\ occupant safety; frontal \\ impact; restraint system; seat \\ belt payout behavior; \\ anthropomorphic test \\ devices (ATDs); postmortem \\ human subjects (PMHS)
}

During an impact, the occupant is decelerated by the seat belt force and pays the belt webbing out of the spool from a retractor to spread force across the human body parts (Flyte and Perchard 1999). The seat belt behavior can be characterized by tension force vs. belt payout curves to describe the interaction between the occupant and the restraint system. As an output of the restraint system, the seat belt behavior can be influenced by different parameters; for example, occupant anthropometries, belt geometry, and crash severities (Mackay and Hill 1995). Sled tests have historically provided the most realistic laboratory model of frontal impacts for the evaluation of the response of both the occupant and the restraint system (Kallieris and Mattern 1974; Schmidt et al. 1974). The occupant response is approximated by postmortem human surrogates (PMHS) with accurate representation of anatomical structures and the ability to produce comparable kinematics and injury (Crandall et al. 2011). Such test data are the primary source for the development of anthropomorphic test devices (ATDs), commonly referred to as dummies, which are widely used in regulatory tests, consumer 
information tests, and restraint research and development. Time histories of the seat belt tension force were usually provided to represent the response of the belt system acting on the occupants (Kallieris et al. 1995; Mertz et al. 1995). However, characterization of seat belt force-payout behavior, especially regarding subject-specific performance, is largely absent from the existing literatures. Actual seat belt loading in a state-of-the-art frontal sled test is still not well understood.

A series of frontal sled tests were performed simulating the occupant under frontal impact loading conditions with the same retractor model (Forman et al. 2008). These tests provide a unique opportunity to investigate contemporary seat belt behavior experimentally under different frontal impact configurations. The goal of this study was to compare and summarize experimentally derived belt force vs. payout behavior over a range of occupant anthropometries and impact severities from the frontal sled tests. Two restraint types were considered: a 3point $\mathrm{SB}$ and a pretensioning, 2-stage progressive FLB. The analysis of the salient seat belt behavior can lead to a full understanding of the influence of occupant characteristics on the restraint system performance in a more realistic manner.

\section{Methods}

\section{Experimental data overview}

This analysis was conducted based on 58 frontal sled tests (Forman et al. 2008). All of the tests were performed in a sled buck representing the rear seat of a typical mid-size passenger car (Figure 1, top), with the retractor mounted on the rear deck of the vehicle and no D-ring was involved (Figure 1, middle). The tests included 4 different ATDs: the Hybrid III 6-year-old (H3 6YO) in a booster seat, the Hybrid III 5th percentile female (H3 AF05), the Hybrid III 50th percentile male (H3 AM50), and the THOR-NT; as well as PMHS of different anthropometries (small, normal, and obese). Two impact severities were considered with the initial velocities of 48 and $29 \mathrm{~km} / \mathrm{h}$. The occupant, referring to either an ATD or a PMHS, was restrained using either a 3-point SB or a pretensioning, 2-stage progressive FLB (Figure 1, bottom). The force limiters in the retractors were operated by yielding an element in the retractor spindle with a prescribed torque. The torque was determined by the tension force experienced in the belt and the radius of the outer layer of the belt wrap around the retractor spindle. The radius of the spindle was $2.03 \mathrm{~cm}$ and the thickness of a single layer of the belt was approximately $0.18 \mathrm{~cm}$.

\section{Seat belt behavior characterization}

The seat belt behavior was characterized by tension force vs. belt payout histories of the shoulder belt. The tension force of the shoulder belt was obtained from the belt tension gauges mounted between the occupant shoulder and the retractor with a sampling rate of $0.1 \mathrm{~ms}$ (Figure 1, middle). This force was taken as the output of the restraint system and hereafter referred to as the "upper shoulder belt force."

To get the belt payout histories, the belt webbing was marked with $1.5-\mathrm{cm}$ increments including the texture lines, which allowed us to resolve the payout in subincrements of 10 divisions
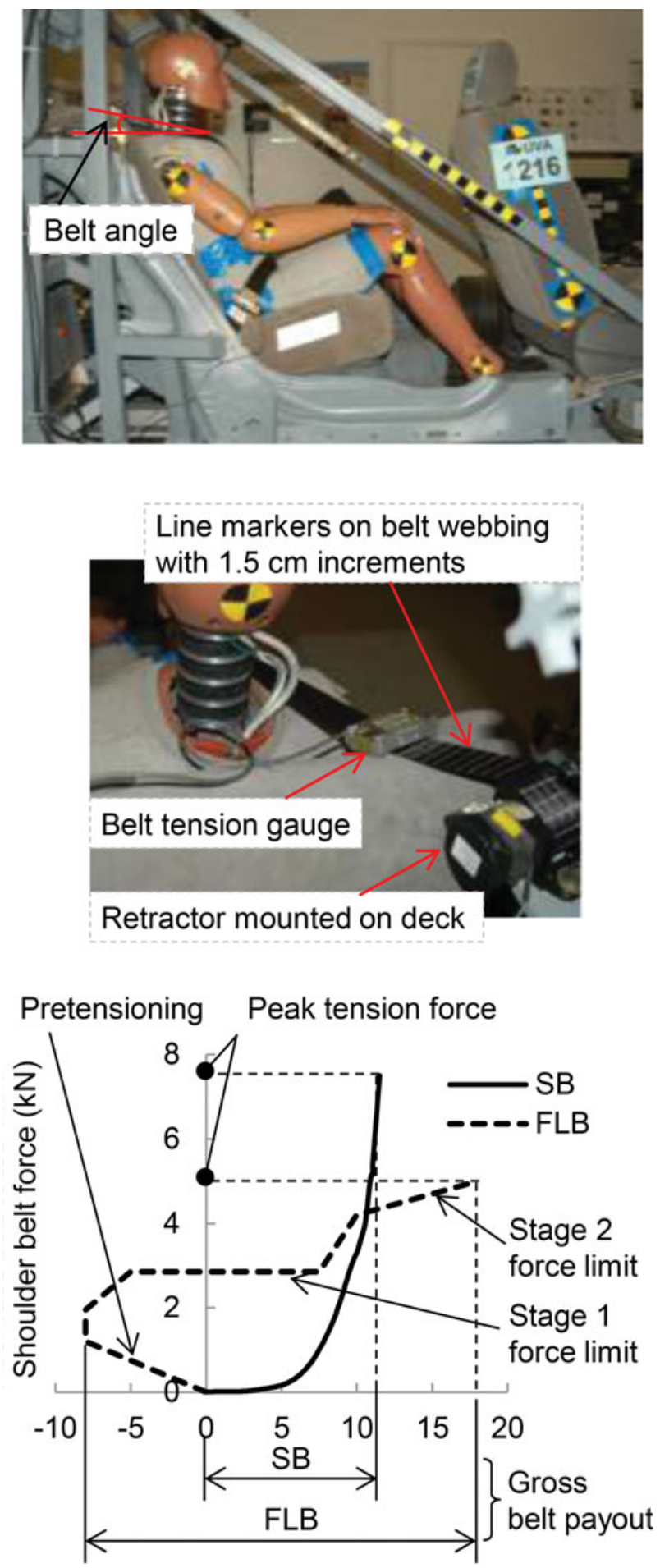

Belt payout $(\mathrm{cm})$

Figure 1. Test setup with the occupant (e.g., ATD H3 AM50) positioned and restrained in the sled buck (passenger side overall view; Forman et al. 2008) (top) position of the deck-mounted retractor (middle); typical force vs. payout curves for the SB and the FLB (bottom).

per primary marking (i.e., $1.5-\mathrm{mm}$ subincrements; Figure 2). The length of belt payout off the retractor was obtained from a dedicated, on-board, high-speed camera with a capture rate of 1,000 fps. The camera recorded the motion of the belt off the retractor as the markings passed a fixed reference point during the impact. Therefore, the payout was measured with a resolution of $1.5 \mathrm{~mm}$ at a sampling rate of $1,000 \mathrm{~Hz}$ and was 


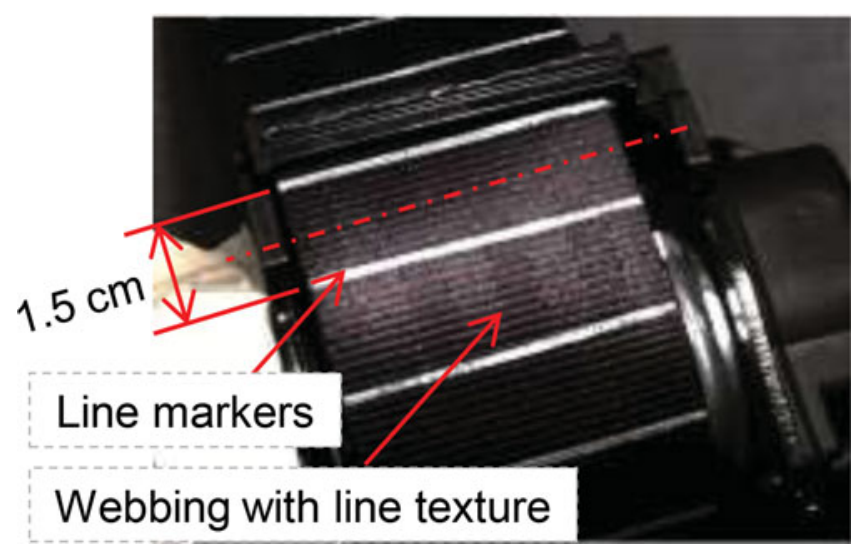

Figure 2. Lines on belt webbing for belt payout measurement in the frontal sled tests.

available up to the maximum payout to plot the force vs. belt payout curves. For SB, the maximum payout was hereafter referred to as the "gross payout"; for FLB, the "gross payout" referred to the length of payout after pretensioning occurred; that is, the sum of the maximum payout and the absolute amount of the negative payout during the pretensioning period (Figure 1, bottom). The belt angle, defined as the lateral angle of the belt from front edge of retractor to the occupant shoulder, was recorded in each experiment (Figure 1, top).

Quantitative and qualitative comparisons of the belt force vs. payout behavior were conducted for each restraint system and impact severity. A univariate linear regression was used to assess the factor significance of the occupant body mass or stature on the peak tension force and gross belt payout for the ATDs and the PMHS. The coefficient and the standard error of the regression model were fitted with the least squares approach. A $t$ test was used to test for differences with a significance level of .05 and the associated $P$ value was calculated.

\section{Results}

\section{Seat belt behavior in frontal impacts with standard belt}

The occupant information and seat belt behavior data are provided in Table 1. The seat belt behavior obtained by ATDs with the SB exhibited similar force slopes regardless of the occupant size, impact severities, or different peak force values (Figure 3, top). Three tests were performed with the ATDs in each test condition and the resultant curves were close to each other; therefore, the averaged seat belt force vs. payout history was provided. The peak shoulder belt forces in the $48 \mathrm{~km} / \mathrm{h}$ tests were $5.2 \pm$ $0.13 \mathrm{kN}$ (H3 6YO), $7.6 \pm 0.39 \mathrm{kN}$ (H3 AF05), $8.7 \pm 0.25 \mathrm{kN}$ (H3 AM50), and $8.2 \pm 0.10 \mathrm{kN}$ (THOR-NT; Forman et al. 2008). The resultant gross belt payouts were $10.2 \pm 0.4,12.5 \pm 0.8,13.2 \pm$ 0.6 , and $13.3 \pm 0.4 \mathrm{~cm}$. With a lower initial impact velocity of $29 \mathrm{~km} / \mathrm{h}$, the peak forces decreased to $3.0 \pm 0.22 \mathrm{kN}$ (H3 6YO), $4.6 \pm 0.18 \mathrm{kN}$ (H3 AF05), $5.3 \pm 0.20 \mathrm{kN}$ (H3 AM50), and 5.6 \pm $0.20 \mathrm{kN}$ (THOR-NT), and the gross payouts were decreased to $8.8 \pm 0.4,11.1 \pm 0.2,9.6 \pm 0.7$, and $10.9 \pm 0.3 \mathrm{~cm}$ (Table 1 ).

The seat belt behavior obtained by PMHS with the SB was found to be more varied than that of the ATDs (Figure 3, bottom). The obese occupant in test 1263 (body mass index $=$
40) loaded the belt system at a 5-cm smaller payout and a subsequently higher force slope relative to the 2 normal-weight subjects (tests 1262 and 1264). Though similar peak tension force was achieved $(6.2 \mathrm{kN}$ for test 1263 and $6.5 \pm 0.33 \mathrm{kN}$ in tests 1262 and 1264), the resultant gross payout was smaller than that for the normal-weight subjects $(8.4 \mathrm{~cm}$ vs. $13.4 \pm 0.42 \mathrm{~cm}$ ). The small subject tested in the booster seat (test 1388) showed a similar force slope but a lower peak force $(4.5 \mathrm{kN})$ compared to the normal-weight subjects.

\section{Seat belt behavior in frontal impacts with force-limiting belt}

The seat belt behavior obtained by ATDs and normal-weight PMHS $(n=3)$ with the FLB under $48 \mathrm{~km} / \mathrm{h}$ provided similar force slopes (Figure 4). The peak shoulder belt forces were $3.1 \pm$ $0.21 \mathrm{kN}$ (H3 6YO), $3.9 \pm 0.19 \mathrm{kN}$ (H3 AF05), $4.4 \pm 0.17 \mathrm{kN}$ (H3 AM50), and $1.7 \pm 0.12 \mathrm{kN}$ (THOR-NT), and the resultant gross belt payouts were $11.6 \pm 0.92 \mathrm{~cm}(\mathrm{H} 36 \mathrm{YO}), 13.46 \pm 0.40 \mathrm{~cm}(\mathrm{H} 3$ AF05), $22.4 \pm 1.92 \mathrm{~cm}$ (H3 AM50), and $23.9 \pm 0.5 \mathrm{~cm}$ (THORNT). Repeatable negative payouts were observed corresponding to the pretensioning stage upon impact. The maximum negative payout was $-8.1 \pm 0.4 \mathrm{~cm}$ for the ATDs under multiple impact configurations, excluding the $\mathrm{H} 36 \mathrm{YO}$ under $29 \mathrm{~km} / \mathrm{h}$ impact. With the impact velocity of $29 \mathrm{~km} / \mathrm{h}$, the $\mathrm{H} 36 \mathrm{YO}$ only used part of the pretensioning stage and no positive payout was observed (Table 1).

For the obese subjects in tests 1333 and 1335, higher restraint force was achieved (Figure 4, bottom), and gross payout was about $5 \mathrm{~cm}$ larger than with the normal-weight subject $(27.0 \pm$ $0.18 \mathrm{~cm}$ vs. $22.2 \pm 0.14 \mathrm{~cm}$ ) or the 50th percentile ATD. Correspondingly, the peak belt force was $2.3 \mathrm{kN}$ higher than the normal-weight subject $(6.6 \pm 0.18 \mathrm{kN}$ vs. $4.4 \pm 0.14 \mathrm{kN})$. The obese subject in test 1335 exhibited a maximum negative payout of $-10.0 \mathrm{~cm}$, which was somewhat higher than the other subjects.

\section{Comparison of the seat belt behavior}

The univariate linear regression results for the groups of ATD and PMHS from the $48 \mathrm{~km} / \mathrm{h}$ test results are shown in Table 2. For the SB, the peak tension force and gross belt payout obtained by the ATDs were highly correlated with occupant stature $(P=$ $.03, P=.02)$ and body mass $(P=.05, P=.04)$. However, for the PMHS with the SB, no statistical difference in occupant stature and body mass were noticed for either the peak force $(P=.09$, $P=.42)$ or gross payout $(P=.40, P=.48)$. With the FLB, the occupant stature and body mass were more significant on the peak force for both ATDs $(P=.02, P=.02)$ and PMHS $(P=$ $.05, P=.00)$ compared to the tests with the SB.

For both SB and FLB, the coefficients of body mass on peak force were higher than zero. This indicated that the maximum belt loading was positively correlated with the body mass during impact (Figure 5, top). Because the occupant mass and stature were coupled to each other, the regression coefficient did not reflect the absolute significance of the parameter as if it were the only variable on the restraint system response. For the FLB, a highly linear relationship was noticed between the occupant body mass and the peak tension force with consideration of both 
depending on the PMHS anthropometry significantly. Therefore, the conventional restraint system modeling approach was acceptable for the ATDs but may not reflect the restraint system response specific to the population variance.

Recent studies on human anthropometry and mesh morphing have been conducted for parametric human body model development to represent the biological variance in a population (Grosland et al. 2009; Hu et al. 2012). Consequently, future restraint modeling efforts should account for the effects of occupant characteristics to mimic real restraint system performance for specific subjects. It is essential to either incorporate occupant information through empirical adjustments of the restraint models or to identify the causal mechanics that link the occupant characteristics to restraint performance and to incorporate them into restraint models deterministically.

An idealized sled test setup has been proposed for both the $\mathrm{SB}$ and the FLB to minimize the possible variance due to the interaction between the test subjects and the restraint system (NHTSA 2011; Shaw et al. 2009, 2012). The tests were performed in a repeatable manner and no retractor module was involved. With extensive data acquisition, the tests will provide a resource for a generalized restraint system model to replicate the idealized loading environment. This paves the way to a computational investigation on the occupant response with consideration of intersubject variability and with limited potential complexities from the restraint system. The contemporary seat belt systems reviewed in this study managed to provide repeatable performance on the ATDs and the peak force was positively correlated to the occupant body mass. To infer the mechanical response of real occupants in a collision, small, normal-weight, and obese PMHS subjects provided an in-depth understanding of the interaction between the occupant and the restraint system. The potential effects of the occupant characteristics need to be included in future experimental setups and computational studies toward optimized, advanced restraint system designs. Further research considering occupant kinematics and injury should be conducted for a full understanding of the biomechanical response resulting from the impact configurations and restrain loadings.

\section{Funding}

The experiments reviewed in this study were funded by the NHTSA and Autoliv Research. The opinions expressed herein are solely those of the authors.

\section{References}

Abbas AK, Hefny AF, Abu-Zidan FM. Seatbelts and road traffic collision injuries. World J Emerg Surg. 2011;6:11-36.

Backaitis SH. Biomechanics of Impact Injury and Injury Tolerances of the Thorax-Shoulder Complex. Warrendale, PA: Society of Automotive Engineers; 1994. Publication PT-45.

Bendjellal F, Trosseille X, Foret-Bruno J, Steyer C, Walfisch G. The combination of a new air bag technology with a belt load limiter. Paper presented at: 22nd International Technical Conference on the Enhanced Safety of Vehicles (ESV); 2011; Windsor, ON, Canada.

Crandall JR, Bose D, Forman JL, et al. Human surrogates for injury biomechanics research. Clin Anat. 2011;24:362-371.

Fauziana L, Kamaliah AN, Atiqah MFS, Wong SV. The benefit of seatbelts in reducing injury severity in frontal collision. Paper presented at: International Crashworthiness Conference; 2012; Milan, Italy.
Flyte MDG, Perchard MF. The prediction of car driver size and position to enhance safety in crashes. Ergonomics. 1999;42:1149-1166.

Foret-Bruno J, Got C, Dandres P, et al. Thoracic injury risk in frontal car crashes with occupant restrained with belt load limiter. Paper presented at: Stapp Car Crash Conference; 1998.

Foret Bruno JY, Trosseille X, Page Y, et al. Comparison of thoracic injury risk in frontal car crashes for occupant restrained without belt load limiters and those restrained with $6 \mathrm{kN}$ and $4 \mathrm{kN}$ belt loader limiters. Stapp Car Crash J. 2001;45:205-224.

Forman JL, Lopez-Valdes FJ, Lessley DJ, Kindig M, Kent RW, Bostrom O. The effect of obesity on the restraint of automobile occupants. Ann Adv Automot Med. 2009;53:25-40.

Forman JL, Michaelson J, Kent RW, Kuppa S, Bostrom O. occupant restraint in the rear seat: ATD responses to standard and pre-tensioning, forcelimiting belt restraints. Ann Adv Automot Med. 2008;52:141-154.

Grosland NM, Bafna R, Magnotta VA. Automated hexahedral meshing of anatomic structures using deformable registration. Comput Methods Biomech Biomed Eng. 2009;12:35-43.

Haland Y. The evolution of the three point seat belt from yesterday to tomorrow. Paper presented at: IRCOBI Conference; 2006; Madrid, Spain.

Hu J, Rupp J, Reed M. Focusing on vulnerable populations in crashes: recent advances in finite element human models for injury biomechanics research. Journal of Automotive Safety and Energy. 2012;3:295-307.

Kallieris D, Mattern R. Shoulder belt forces and thorax injuries. Paper presented at: IRCOBI Conference; 1974.

Kallieris D, Rizzetti A, Mattern R, Morgan R, Eppinger R, Keenen L. On the synergism of the driver air bag and the 3-point belt in frontal collisions. Paper presented at: Stapp Car Crash Conference; 1995.

Kent RW, Forman JL, Bostrom O. Is there really a "cushion effect"? A biomechanical investigation of crash injury mechanisms in the obese. Obesity. 2010;18:749-753.

Kitagawa Y, Yasuki T. Correlation among seatbelt load, chest deflection, rib fracture and internal organ strain in frontal collisions with human body finite element models. Paper presented at: IRCOBI Conference; 2013; Gothenburg, Sweden.

Lopez-Valdes FJ, Juste O, Pipkorn B, et al. A comparison of the performance of two advanced restraint systems in frontal impacts. Traffic Inj Prev. 2014;15(Suppl 1):S119-S125.

Mackay G, Hill J. The limitations of current seatbelts in Europe-some population considerations. J Trauma. 1995;38:533-537.

Mertz H, Williamson J, Vander Lugt D. The Effect of Limiting Shoulder Belt Load with Air Bag Restraint. Warrendale, PA: Society of Automotive Engineers; 1995. SAE No. 950886.

Mizuno K, Matsui Y, Ikari T, Toritsuka T. Seatbelt effectiveness for rear seat occupants in full and offset frontal crash tests. Int J Crashworthiness. 2011;16:63-74.

Mulligan GWN, Pizey GS, Lane D, Andersson L, English C, Kohut C. An introduction to the understanding of blunt chest trauma. In: Backaitis SH, ed. Biomechanics of Impact Injury and Injury Tolerance of the Thorax-Shoulder Complex. Warrendale, PA: Society of Automotive Engineers; 1994:11-36.

NHTSA, US Department of Transportation. NHTSA's Biomechanics Research Plan, 2011-2015. 2011. Available at: http://www.nhtsa.gov. Accessed June 2011.

Reed M, Ebert-Hamilton S. Distribution of belt anchorage locations in the second row of passenger cars and light trucks. J Transp Saf. 2013;1:2531.

Schmidt G, Kallieris D, Barz J, Mattern R. Results of 49 cadaver tests simulating frontal collision of front seat passengers. Paper presented at: Stapp Car Crash Conference; 1974.

Shaw CG, Lessley DJ, Ash JH, Crandall JR. Development of an alternative frontal impact condition to assess thoracic response using the THOR Mod Kit dummy. Paper presented at: JSAE Annual Congress; 2012; Yokohama, Japan.

Shaw CG, Parent DP, Purtsezov S, et al. Impact response of restrained PMHS in frontal sled tests: skeletal deformation patterns under seat belt loading. Stapp Car Crash J. 2009;53:1-48.

Viano DC, Parenteau CS, Edwards ML. Crash injury risks for obese occupants using a matched-pair analysis. Traffic Inj Prev. 2008;9:59-64.

Walz M. NCAP test improvements with pretensioners and load limiters. Traffic Inj Prev. 2004;5:18-25. 

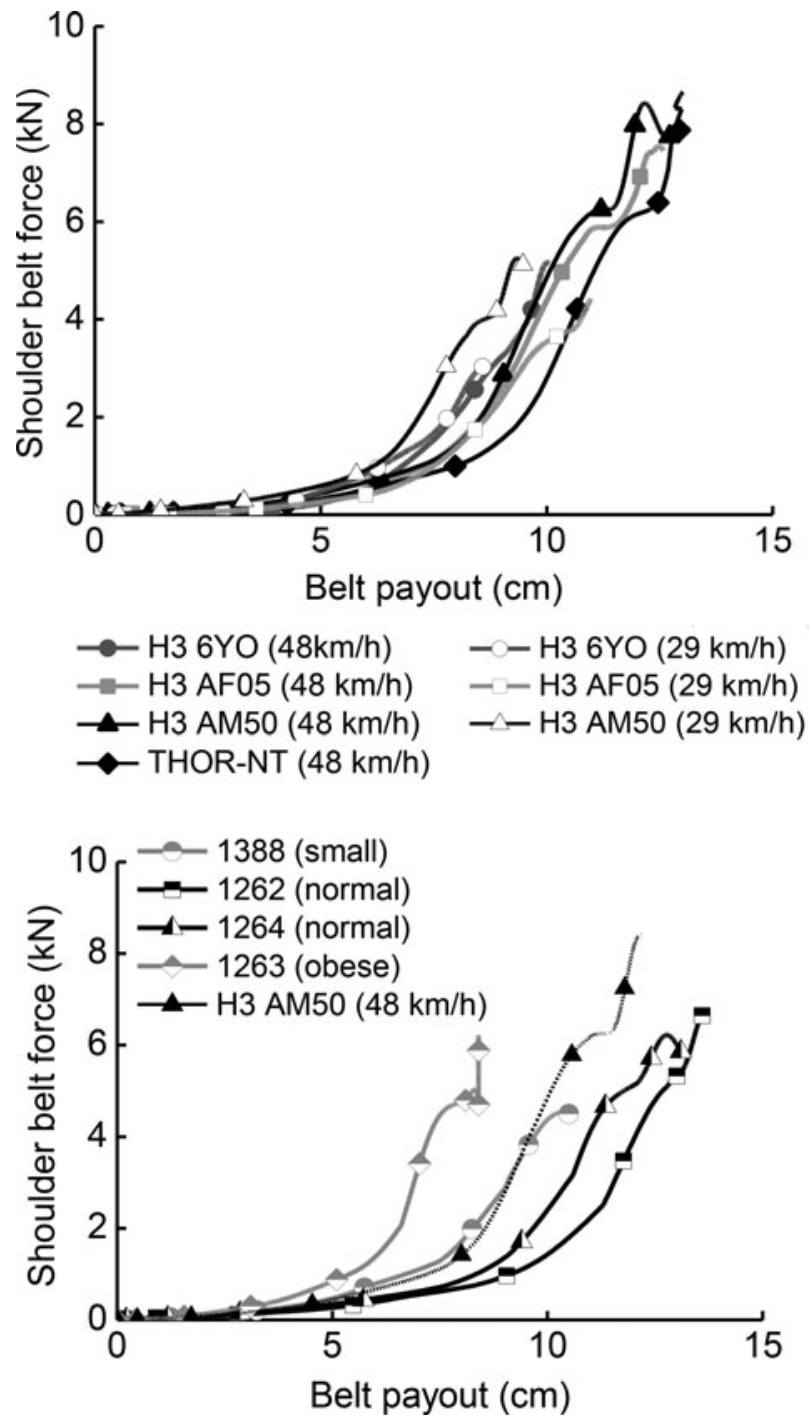

Figure 3. Upper shoulder belt force vs. payout histories with the SB: ATDs in the 48 and $29 \mathrm{~km} / \mathrm{h}$ tests (top) and PMHS in the $48 \mathrm{~km} / \mathrm{h}$ tests (bottom).

for the tests with FLB, the amount of belt wrapped around the spindle at the time of peak tension force was on average approximately $11 \mathrm{~cm}$ for obese subjects and $52 \mathrm{~cm}$ for normal-weight subjects. Given the spindle and belt layer geometry described in the experimental setup, this resulted in 0.8 wraps of belt around the spindle and an outer spindle belt radius of $2.18 \mathrm{~cm}$ for obese subjects and 4.1 wraps and a $2.75-\mathrm{cm}$ outer spindle belt radius for normal-weight subjects. This $26 \%$ higher average radius in the normal-weight subjects relative to obese subjects accounted for a substantial portion of the observed difference in peak force $(4.4 \pm 0.14 \mathrm{kN}$ vs. $6.6 \pm 0.18 \mathrm{kN}$; Figure 4, bottom). The pretensioning stage also contributed to the variation in tension force for the tested PMHS with FLB. The obese subject in test 1333 had a higher negative belt payout up to $10.0 \mathrm{~cm}$. This was potentially due to the compliance of the superficial tissue associated with the obesity, which would result in compression when pretensioning occurred.

However, the ATDs were not able to provide much difference in the initial belt payout before the impact began for the tests reviewed in this study. The $\mathrm{H} 36 \mathrm{YO}$ was tested in a booster seat, and the H3 AF05 was positioned in a manner similar to that
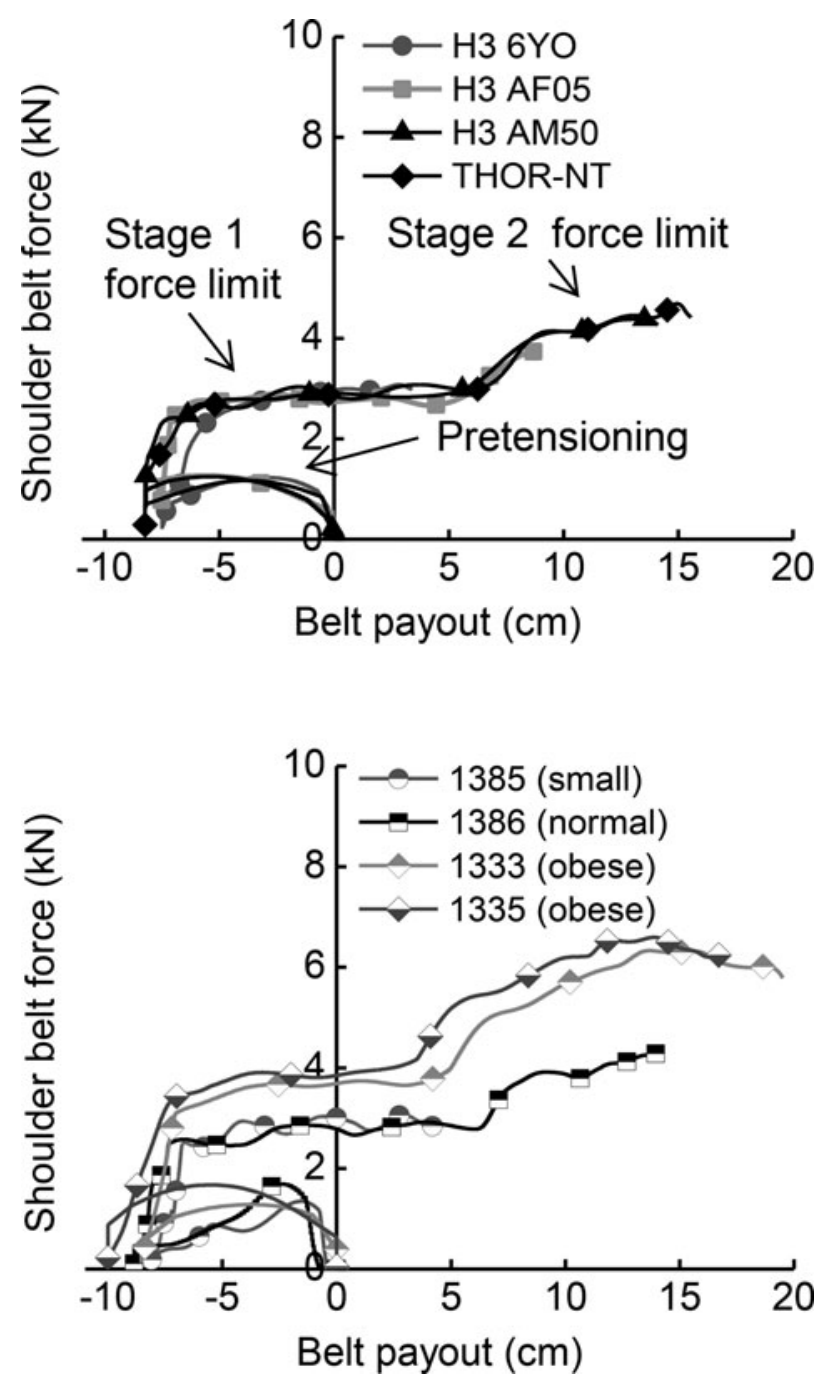

Figure 4. Upper shoulder belt force vs. payout histories with the FLB in the $48 \mathrm{~km} / \mathrm{h}$ tests: ATDs (top) and PMHS (bottom).

of the H3 AM50. The observed difference between the ATDs and the PMHS can be explained as one of the limitations of the current dummy development: the morphology studied corresponded to normal-weight anthropometries for different body sizes and no obese dummy was studied.

The restraint forces from seat belts are typically designed based on target characteristic load curves considered when designing the retractor system. However, with the occupantspecific belt fit, the force vs. payout curves and the restraint performance may be different than the original design targets. For example, a systematic biomechanical interaction was noticed in obese subjects with the FLB: the belt system appeared to effectively self-adjust for increased occupant mass as a result of differences in the belt fit and length remaining on the spindle (Figure 4, bottom). Though this may be favorable from an energy management standpoint, the increased force applied to the subject may cause other secondary effects such as increased thoracic injury risk. The results of this study suggest that the anthropometric variations in the population can affect restraint system performance in a manner that was not typically observed with ATDs, even when tests were performed with ATDs of different sizes. 
depending on the PMHS anthropometry significantly. Therefore, the conventional restraint system modeling approach was acceptable for the ATDs but may not reflect the restraint system response specific to the population variance.

Recent studies on human anthropometry and mesh morphing have been conducted for parametric human body model development to represent the biological variance in a population (Grosland et al. 2009; Hu et al. 2012). Consequently, future restraint modeling efforts should account for the effects of occupant characteristics to mimic real restraint system performance for specific subjects. It is essential to either incorporate occupant information through empirical adjustments of the restraint models or to identify the causal mechanics that link the occupant characteristics to restraint performance and to incorporate them into restraint models deterministically.

An idealized sled test setup has been proposed for both the $\mathrm{SB}$ and the FLB to minimize the possible variance due to the interaction between the test subjects and the restraint system (NHTSA 2011; Shaw et al. 2009, 2012). The tests were performed in a repeatable manner and no retractor module was involved. With extensive data acquisition, the tests will provide a resource for a generalized restraint system model to replicate the idealized loading environment. This paves the way to a computational investigation on the occupant response with consideration of intersubject variability and with limited potential complexities from the restraint system. The contemporary seat belt systems reviewed in this study managed to provide repeatable performance on the ATDs and the peak force was positively correlated to the occupant body mass. To infer the mechanical response of real occupants in a collision, small, normal-weight, and obese PMHS subjects provided an in-depth understanding of the interaction between the occupant and the restraint system. The potential effects of the occupant characteristics need to be included in future experimental setups and computational studies toward optimized, advanced restraint system designs. Further research considering occupant kinematics and injury should be conducted for a full understanding of the biomechanical response resulting from the impact configurations and restrain loadings.

\section{Funding}

The experiments reviewed in this study were funded by the NHTSA and Autoliv Research. The opinions expressed herein are solely those of the authors.

\section{References}

Abbas AK, Hefny AF, Abu-Zidan FM. Seatbelts and road traffic collision injuries. World J Emerg Surg. 2011;6:11-36.

Backaitis SH. Biomechanics of Impact Injury and Injury Tolerances of the Thorax-Shoulder Complex. Warrendale, PA: Society of Automotive Engineers; 1994. Publication PT-45.

Bendjellal F, Trosseille X, Foret-Bruno J, Steyer C, Walfisch G. The combination of a new air bag technology with a belt load limiter. Paper presented at: 22nd International Technical Conference on the Enhanced Safety of Vehicles (ESV); 2011; Windsor, ON, Canada.

Crandall JR, Bose D, Forman JL, et al. Human surrogates for injury biomechanics research. Clin Anat. 2011;24:362-371.

Fauziana L, Kamaliah AN, Atiqah MFS, Wong SV. The benefit of seatbelts in reducing injury severity in frontal collision. Paper presented at: International Crashworthiness Conference; 2012; Milan, Italy.
Flyte MDG, Perchard MF. The prediction of car driver size and position to enhance safety in crashes. Ergonomics. 1999;42:1149-1166.

Foret-Bruno J, Got C, Dandres P, et al. Thoracic injury risk in frontal car crashes with occupant restrained with belt load limiter. Paper presented at: Stapp Car Crash Conference; 1998.

Foret Bruno JY, Trosseille X, Page Y, et al. Comparison of thoracic injury risk in frontal car crashes for occupant restrained without belt load limiters and those restrained with $6 \mathrm{kN}$ and $4 \mathrm{kN}$ belt loader limiters. Stapp Car Crash J. 2001;45:205-224.

Forman JL, Lopez-Valdes FJ, Lessley DJ, Kindig M, Kent RW, Bostrom O. The effect of obesity on the restraint of automobile occupants. Ann Adv Automot Med. 2009;53:25-40.

Forman JL, Michaelson J, Kent RW, Kuppa S, Bostrom O. occupant restraint in the rear seat: ATD responses to standard and pre-tensioning, forcelimiting belt restraints. Ann Adv Automot Med. 2008;52:141-154.

Grosland NM, Bafna R, Magnotta VA. Automated hexahedral meshing of anatomic structures using deformable registration. Comput Methods Biomech Biomed Eng. 2009;12:35-43.

Haland Y. The evolution of the three point seat belt from yesterday to tomorrow. Paper presented at: IRCOBI Conference; 2006; Madrid, Spain.

Hu J, Rupp J, Reed M. Focusing on vulnerable populations in crashes: recent advances in finite element human models for injury biomechanics research. Journal of Automotive Safety and Energy. 2012;3:295-307.

Kallieris D, Mattern R. Shoulder belt forces and thorax injuries. Paper presented at: IRCOBI Conference; 1974.

Kallieris D, Rizzetti A, Mattern R, Morgan R, Eppinger R, Keenen L. On the synergism of the driver air bag and the 3-point belt in frontal collisions. Paper presented at: Stapp Car Crash Conference; 1995.

Kent RW, Forman JL, Bostrom O. Is there really a "cushion effect"? A biomechanical investigation of crash injury mechanisms in the obese. Obesity. 2010;18:749-753.

Kitagawa Y, Yasuki T. Correlation among seatbelt load, chest deflection, rib fracture and internal organ strain in frontal collisions with human body finite element models. Paper presented at: IRCOBI Conference; 2013; Gothenburg, Sweden.

Lopez-Valdes FJ, Juste O, Pipkorn B, et al. A comparison of the performance of two advanced restraint systems in frontal impacts. Traffic Inj Prev. 2014;15(Suppl 1):S119-S125.

Mackay G, Hill J. The limitations of current seatbelts in Europe-some population considerations. J Trauma. 1995;38:533-537.

Mertz H, Williamson J, Vander Lugt D. The Effect of Limiting Shoulder Belt Load with Air Bag Restraint. Warrendale, PA: Society of Automotive Engineers; 1995. SAE No. 950886.

Mizuno K, Matsui Y, Ikari T, Toritsuka T. Seatbelt effectiveness for rear seat occupants in full and offset frontal crash tests. Int J Crashworthiness. 2011;16:63-74.

Mulligan GWN, Pizey GS, Lane D, Andersson L, English C, Kohut C. An introduction to the understanding of blunt chest trauma. In: Backaitis SH, ed. Biomechanics of Impact Injury and Injury Tolerance of the Thorax-Shoulder Complex. Warrendale, PA: Society of Automotive Engineers; 1994:11-36.

NHTSA, US Department of Transportation. NHTSA's Biomechanics Research Plan, 2011-2015. 2011. Available at: http://www.nhtsa.gov. Accessed June 2011.

Reed M, Ebert-Hamilton S. Distribution of belt anchorage locations in the second row of passenger cars and light trucks. J Transp Saf. 2013;1:2531.

Schmidt G, Kallieris D, Barz J, Mattern R. Results of 49 cadaver tests simulating frontal collision of front seat passengers. Paper presented at: Stapp Car Crash Conference; 1974.

Shaw CG, Lessley DJ, Ash JH, Crandall JR. Development of an alternative frontal impact condition to assess thoracic response using the THOR Mod Kit dummy. Paper presented at: JSAE Annual Congress; 2012; Yokohama, Japan.

Shaw CG, Parent DP, Purtsezov S, et al. Impact response of restrained PMHS in frontal sled tests: skeletal deformation patterns under seat belt loading. Stapp Car Crash J. 2009;53:1-48.

Viano DC, Parenteau CS, Edwards ML. Crash injury risks for obese occupants using a matched-pair analysis. Traffic Inj Prev. 2008;9:59-64.

Walz M. NCAP test improvements with pretensioners and load limiters. Traffic Inj Prev. 2004;5:18-25. 
depending on the PMHS anthropometry significantly. Therefore, the conventional restraint system modeling approach was acceptable for the ATDs but may not reflect the restraint system response specific to the population variance.

Recent studies on human anthropometry and mesh morphing have been conducted for parametric human body model development to represent the biological variance in a population (Grosland et al. 2009; Hu et al. 2012). Consequently, future restraint modeling efforts should account for the effects of occupant characteristics to mimic real restraint system performance for specific subjects. It is essential to either incorporate occupant information through empirical adjustments of the restraint models or to identify the causal mechanics that link the occupant characteristics to restraint performance and to incorporate them into restraint models deterministically.

An idealized sled test setup has been proposed for both the $\mathrm{SB}$ and the FLB to minimize the possible variance due to the interaction between the test subjects and the restraint system (NHTSA 2011; Shaw et al. 2009, 2012). The tests were performed in a repeatable manner and no retractor module was involved. With extensive data acquisition, the tests will provide a resource for a generalized restraint system model to replicate the idealized loading environment. This paves the way to a computational investigation on the occupant response with consideration of intersubject variability and with limited potential complexities from the restraint system. The contemporary seat belt systems reviewed in this study managed to provide repeatable performance on the ATDs and the peak force was positively correlated to the occupant body mass. To infer the mechanical response of real occupants in a collision, small, normal-weight, and obese PMHS subjects provided an in-depth understanding of the interaction between the occupant and the restraint system. The potential effects of the occupant characteristics need to be included in future experimental setups and computational studies toward optimized, advanced restraint system designs. Further research considering occupant kinematics and injury should be conducted for a full understanding of the biomechanical response resulting from the impact configurations and restrain loadings.

\section{Funding}

The experiments reviewed in this study were funded by the NHTSA and Autoliv Research. The opinions expressed herein are solely those of the authors.

\section{References}

Abbas AK, Hefny AF, Abu-Zidan FM. Seatbelts and road traffic collision injuries. World J Emerg Surg. 2011;6:11-36.

Backaitis SH. Biomechanics of Impact Injury and Injury Tolerances of the Thorax-Shoulder Complex. Warrendale, PA: Society of Automotive Engineers; 1994. Publication PT-45.

Bendjellal F, Trosseille X, Foret-Bruno J, Steyer C, Walfisch G. The combination of a new air bag technology with a belt load limiter. Paper presented at: 22nd International Technical Conference on the Enhanced Safety of Vehicles (ESV); 2011; Windsor, ON, Canada.

Crandall JR, Bose D, Forman JL, et al. Human surrogates for injury biomechanics research. Clin Anat. 2011;24:362-371.

Fauziana L, Kamaliah AN, Atiqah MFS, Wong SV. The benefit of seatbelts in reducing injury severity in frontal collision. Paper presented at: International Crashworthiness Conference; 2012; Milan, Italy.
Flyte MDG, Perchard MF. The prediction of car driver size and position to enhance safety in crashes. Ergonomics. 1999;42:1149-1166.

Foret-Bruno J, Got C, Dandres P, et al. Thoracic injury risk in frontal car crashes with occupant restrained with belt load limiter. Paper presented at: Stapp Car Crash Conference; 1998.

Foret Bruno JY, Trosseille X, Page Y, et al. Comparison of thoracic injury risk in frontal car crashes for occupant restrained without belt load limiters and those restrained with $6 \mathrm{kN}$ and $4 \mathrm{kN}$ belt loader limiters. Stapp Car Crash J. 2001;45:205-224.

Forman JL, Lopez-Valdes FJ, Lessley DJ, Kindig M, Kent RW, Bostrom O. The effect of obesity on the restraint of automobile occupants. Ann Adv Automot Med. 2009;53:25-40.

Forman JL, Michaelson J, Kent RW, Kuppa S, Bostrom O. occupant restraint in the rear seat: ATD responses to standard and pre-tensioning, forcelimiting belt restraints. Ann Adv Automot Med. 2008;52:141-154.

Grosland NM, Bafna R, Magnotta VA. Automated hexahedral meshing of anatomic structures using deformable registration. Comput Methods Biomech Biomed Eng. 2009;12:35-43.

Haland Y. The evolution of the three point seat belt from yesterday to tomorrow. Paper presented at: IRCOBI Conference; 2006; Madrid, Spain.

Hu J, Rupp J, Reed M. Focusing on vulnerable populations in crashes: recent advances in finite element human models for injury biomechanics research. Journal of Automotive Safety and Energy. 2012;3:295-307.

Kallieris D, Mattern R. Shoulder belt forces and thorax injuries. Paper presented at: IRCOBI Conference; 1974.

Kallieris D, Rizzetti A, Mattern R, Morgan R, Eppinger R, Keenen L. On the synergism of the driver air bag and the 3-point belt in frontal collisions. Paper presented at: Stapp Car Crash Conference; 1995.

Kent RW, Forman JL, Bostrom O. Is there really a "cushion effect"? A biomechanical investigation of crash injury mechanisms in the obese. Obesity. 2010;18:749-753.

Kitagawa Y, Yasuki T. Correlation among seatbelt load, chest deflection, rib fracture and internal organ strain in frontal collisions with human body finite element models. Paper presented at: IRCOBI Conference; 2013; Gothenburg, Sweden.

Lopez-Valdes FJ, Juste O, Pipkorn B, et al. A comparison of the performance of two advanced restraint systems in frontal impacts. Traffic Inj Prev. 2014;15(Suppl 1):S119-S125.

Mackay G, Hill J. The limitations of current seatbelts in Europe-some population considerations. J Trauma. 1995;38:533-537.

Mertz H, Williamson J, Vander Lugt D. The Effect of Limiting Shoulder Belt Load with Air Bag Restraint. Warrendale, PA: Society of Automotive Engineers; 1995. SAE No. 950886.

Mizuno K, Matsui Y, Ikari T, Toritsuka T. Seatbelt effectiveness for rear seat occupants in full and offset frontal crash tests. Int J Crashworthiness. 2011;16:63-74.

Mulligan GWN, Pizey GS, Lane D, Andersson L, English C, Kohut C. An introduction to the understanding of blunt chest trauma. In: Backaitis SH, ed. Biomechanics of Impact Injury and Injury Tolerance of the Thorax-Shoulder Complex. Warrendale, PA: Society of Automotive Engineers; 1994:11-36.

NHTSA, US Department of Transportation. NHTSA's Biomechanics Research Plan, 2011-2015. 2011. Available at: http://www.nhtsa.gov. Accessed June 2011.

Reed M, Ebert-Hamilton S. Distribution of belt anchorage locations in the second row of passenger cars and light trucks. J Transp Saf. 2013;1:2531.

Schmidt G, Kallieris D, Barz J, Mattern R. Results of 49 cadaver tests simulating frontal collision of front seat passengers. Paper presented at: Stapp Car Crash Conference; 1974.

Shaw CG, Lessley DJ, Ash JH, Crandall JR. Development of an alternative frontal impact condition to assess thoracic response using the THOR Mod Kit dummy. Paper presented at: JSAE Annual Congress; 2012; Yokohama, Japan.

Shaw CG, Parent DP, Purtsezov S, et al. Impact response of restrained PMHS in frontal sled tests: skeletal deformation patterns under seat belt loading. Stapp Car Crash J. 2009;53:1-48.

Viano DC, Parenteau CS, Edwards ML. Crash injury risks for obese occupants using a matched-pair analysis. Traffic Inj Prev. 2008;9:59-64.

Walz M. NCAP test improvements with pretensioners and load limiters. Traffic Inj Prev. 2004;5:18-25. 